\title{
POSTURAL HYPOTENSION: THE LOCALIZATION OF THE LESION
}

\author{
BY \\ D. VEREL* \\ From the Clinical Research Unit, Guy's Hospital \\ Received June 21, 1950
}

Since postural hypotension was first described by Bradbury and Eggleston in 1925, many reports have been published of patients in whom a great fall in blood pressure occurred on standing. In such cases the blood pressure is usually normal while the patient is horizontal, but falls progressively as he approaches the standing position, and does not rise again until he once more reclines. The cases fall into two groups. In one the disorder is associated with disease of the nervous or endocrine systems, and may be termed symptomatic postural hypotension. In the other no gross evidence of disease is found : some 36 reported cases are of this type, which, as suggested by Bradbury and Eggleston, appears to be a clinical entity to which the term idiopathic postural hypotension may be applied.

Patients with either type of postural hypotension may show similar features. With the great fall in blood pressure that occurs on standing erect, there is often no change in pulse rate, and syncope may occur but is unassociated with nausea and immediately relieved by lying flat. Anhidrosis, frequently patchy in distribution, and nocturnal polyuria are usual in the idiopathic type, and loss of libido may occur. As these features are sometimes found in cases of the symptomatic type, the diagnosis of idiopathic postural hypotension depends on the exclusion of known causes.

The disorder of function responsible for idiopathic postural hypotension has not yet been established beyond dispute. In 1941 Stead and Ebert, and Jeffers et al., independently attributed the postural hypotension to a failure of reflex vasoconstriction in response to a fall in blood pressure. They measured the blood flow in the finger or hand and found a rate that they thought higher than normal for a comparable fall in blood pressure. They inferred from this that the normal vasoconstriction had not occurred in the limbs of their cases of postural hypotension. Barcroft and Edholm (1945), however, have shown that the hand blood flow during the very low blood pressures of the vasovagal reaction of Lewis may be as high or higher than that reported by Stead and Ebert in postural hypotension, and so no certain conclusion may be drawn from observations of blood flow. Vasomotor reflex activity in response to other stimuli also fails to provide indisputable evidence, for Stead and Ebert found that their case showed normal vasoconstriction in response to pinching, while Jeffers et al. could not demonstrate any response to a loud noise.

In this paper observations on three cases of idiopathic postural hypotension are reported, and it is concluded that the fall in blood pressure is due to a central failure of reflex vasoconstriction.

The first case has been observed over four years and her history is given at some length as changes occurred in her condition during this time which have not been previously described in this disease.

Case 1. Mrs. A. M., aged 54, was first seen in February, 1946. .Three years previously she began to have attacks of giddiness lasting for a few moments while out walking, and would cling to a tree or lamp post for support. She said she had not sweated since that time, although previously she sweated normally, for example, while she was about her housework. Eighteen months later she fainted without warning in the

* Beit Memorial Research Fellow. 
street, and since then had fainted frequently, always while erect and especially if she stood still. The frequency and ease with which she fainted varied considerably from day to day, but she had noticed no relation either to the temperature or time of day. Apart from faint pigmentation of the abdomen resembling vitiligo, which had first been noticed 18 months before, no abnormality was found on routine examination. Her blood pressure supine was $160 / 90 \mathrm{~mm}$. $\mathrm{Hg}$. When she sat up in bed it fell in three minutes to 100/70.

Addison's disease was thought to be excluded by the normal serum sodium and potassium and by a normal water excretion test. The Wassermann reaction was negative and in the absence of any abnormal signs in the nervous system a diagnosis of idiopathic postural hypotension was made.

The postural hypotension persisted throughout four years' observation, and the variation in the ease with which syncope might come on was constantly present. At times when the patient felt "no good" she walked slowly about dragging her feet along, her manner was languid, and she became dizzy after walking up five or six steps. When she was " all right " her step was firm, her manner brisk, and she walked upstairs confidently. Until August, 1948, these variations occurred without warning or associated phenomena, but after that month the patient found that when she was all right her hands and feet felt hot and she could feel sweat on the palms of the hands, over her nose and most of her forehead. This was confirmed in April, 1949, when she was examined in her well phase. Her face and hands were found to be warm though her face had its customary pallor, her palms were moist, and her face slightly sweaty, particularly over the forehead and nose. The skin had been examined several times previously in hot weather or after syncope for the presence of sweat, and these areas had always been found to be dry. Two sweating tests had been performed, and although profuse sweating had occurred elsewhere, these areas had on both occasions been free from sweat. On standing the usual fall in blood pressure occurred. This appearance of sweat on her hands and face with a feeling of heat was so reliable a sign that she was not likely to faint that she was in the habit of waiting for it before venturing out of doors. These episodes of well being usually lasted for a few hours, sometimes all day, and were quite unpredictable in their appearance. The onset was usually clear-cut, for example, once while sitting by the fire, the feeling of warmth came on, she found her hands and face moist, and she went to the cinema; while there the episode passed and she fainted in the foyer on leaving.

Another change of some interest was found in April, 1949. On all previous occasions a marked fall in blood pressure had been accompanied by an increase of pulse rate from about 70 to about 115 a minute. Now a bradycardia occurred. After two hours horizontal the blood pressure supine was 200/105, the pulse rate 72. On sitting up in bed these figures fell to $140 / 90$ and 68, and on standing, fellfurtherto $95 / 50$ and 60 .

Symptomatic relief was obtained by a tight abdominal binder and the " head-up " bed regime (MacLean and Allen, 1940), the patient not lying horizontal at any time by day or night, and sleeping on a bed whose head is blocked up. The effects are easily reversible, and it was frequently found that even a few hours supine caused a return to the previous state (MacLean and Allen, 1940). Even in her phases of feeling "all right" she was liable to faint if she had been sleeping horizontal. The observation that the head-up bed regime greatly slows the fall in blood pressure on standing (MacLean, Allen, and Magath, 1944) was repeatedly confirmed, the pressure taking about ten minutes to fall as far as it would fall in two to three minutes without treatment.

Case 2. Mrs. N. W., aged 67, had been in good health until ten years before when she began to have attacks of giddiness, leading to syncope if she did not sit down. At first they occurred only on odd days with months of freedom between, but for some years she had been having two to three " bad days " when syncopal attacks were very frequent, followed by two to three weeks when she could walk about a little, although she had to sit down often. She could not stand still for more than a few seconds at any time, and did her housework from a chair. Fainting usually occurred on first getting out of bed, and was less frequent later in the day. Attacks were more common in hot weather. She did not remember ever having sweated.

No abnormality was found on physical examination. While supine her blood pressure was 130/80; on sitting up in bed it fell in two minutes to $80 / 55$, and on standing a further fall to $60 / 45$ occurred. The pulse rate increased from 82 to 88 a minute. Her serum sodium and chloride were normal, $\mathrm{Hb} 80$ per cent and blood urea $53 \mathrm{mg}$. per $100 \mathrm{ml}$. Some improvement was obtained from elastic stockings and a tight abdominal binder, but the head-up bed position caused no change in her condition.

Case 3. Mr. W. H., aged 57, For 3 years he had had attacks of blurring vision while standing or walking, and for 2 years transient dizziness while erect without loss of consciousness. These occurred once or twice a week, and were more likely to come on when he was standing than walking. For 6 months attacks of loss of consciousness had occurred at infrequent intervals, always coming on when standing still. He frequently felt dizzy, but would avoid fainting by sitting down and putting his head between his knees. Attacks were more frequent early in the day, and he had noticed that on some days he felt very well with little tendency to faint, while on other days he was " no good for anything." For about one year he had been easily tired. He thought he had been sweating less recently. He had had no sexual intercourse for 4 to 5 years, and his erections and emissions had been feeble for 9 months and absent for 4 or 5 months. His wife was a chronic invalid. 
He appeared a healthy, rubicund countryman. Routine physical examination revealed no abnormality except varicose veins in the right leg apart from the effect of change of posture on the blood pressure. While supine the blood pressure was 140/85, pulse rate 64 ; on sitting up 120/75, pulse 84 ; when erect after 3 minutes, 55/?, pulse 112 .

His serum potassium, serum sodium, blood cholesterol, and blood urea were normal. The Wassermann reaction and blood count were also normal.

The head-up bed position seemed to be beneficial, but the period of observation was not enough to permit a certain opinion of its value.

Change of posture had a similar effect in all cases. On standing the rate and depth of respiration increased as the blood pressure fell, until, with a systolic pressure of $60 \mathrm{~mm} . \mathrm{Hg}$, the respiratory rate was usually between 25 and 30 a minute. Dizziness was complained of, and the first case often noticed that her mouth was dry. If the erect position was maintained a coarse tremor next appeared, affecting the left hand in the first case, and all four limbs in the second. In the third no tremor was noted, but a hoarse cry preceded the onset of syncope. In the first case the respirations became noisy and grunting after some minutes, but in the others this was not so evident. Finally, syncope occurred after a time varying from $2 \frac{1}{2}$ to 20 minutes. All cases said that loss of consciousness was preceded by visual upsets: in the first " everything went black," but the second noted first blurring of the vision, then a heliotrope hue, and finally white; the third noted blurring of vision. All three had learned to avert syncope whenever dizziness came on by sitting down quickly, but attacks might occur without warning. None had noticed nausea ; nor did yawning, belching or vomiting occur. In the first case electrocardiography showed that the heart rate was not slowed during syncope. No record of the pulse or heart rate was obtained during syncope in the others, but the heart rate was not slowed immediately before or after syncope. During syncope no pulsation could be felt in the carotid or radial artery of any case, and the heart sounds were inaudible.

\section{OBSERVATIONS}

Other procedures besides change in posture caused abnormal changes in blood pressure. The excessive fall in blood pressure caused by glyceryl trinitrate (Jeffers et al., 1941) and by reactive hyperæmia (Stead and Ebert, 1941) was shown to occur in the first case investigated, and in all these the same effect was produced by trapping blood in the lower limbs by inflating cuffs round the thighs to diastolic pressure. The volume of blood trapped in the legs of the first case in this way was estimated to be approximately 1.9 and 1.8 litres on two occasions by the method of Smirk (1933). This was found to be within normal limits, and agrees with the observation of Stead and Ebert that in two of their cases the volume of blood present in the lower limbs when the patients were upright was normal. The results are shown in Table $\mathrm{I}$.

Failure to regulate the blood pressure could be shown in other ways. For example, blowing a mercury column up to $40 \mathrm{~mm}$. with the glottis open (Flack, 1921) caused a fall in blood pressure while the patient was supine as in the case described by East and Brigden (1946) ; and, in the erect position, dizziness after a few seconds, and syncope after about 10 seconds, in all cases (Maclean and Allen, 1940). Even taking a moderately deep breath and holding it without straining caused a fall in blood pressure of 15 to $40 \mathrm{~mm}$. $\mathrm{Hg}$ systolic when the subject was supine, and the rapid onset of dizziness if erect.

It is clear from what has been said that the sequence of events differed from that in ordinary fainting attacks. Thus, in postural hypotension the blood pressure fell to low levels within two minutes of standing, and remained low while the subjects stood. The increase in pulse rate in two cases when the blood pressure fell, the absence of slowing of the heart rate in syncope in Case 1 and the absence of arterial pulses in all cases during syncope also differed from the findings in fainting (Lewis, 1932). The sudden fall of blood pressure in fainting has been shown to be due to vasodilatation in muscle (Barcroft and Edholm, 1945). The muscle blood flow in postural hypotension has 
TABLE I

Effect on Blood Pressure of Pooling Blood in the Legs

\begin{tabular}{|c|c|c|c|c|c|}
\hline & \multicolumn{2}{|c|}{ Blood Pressure } & \multicolumn{2}{|c|}{ Pulse Rate } & \multirow{2}{*}{$\begin{array}{c}\begin{array}{r}\text { Blood } \\
\text { Pooled }\end{array} \\
\text { (litres) }\end{array}$} \\
\hline & Initial & $\begin{array}{c}\text { After } \\
\text { Pooling }\end{array}$ & Initial & $\begin{array}{c}\text { After } \\
\text { Pooling }\end{array}$ & \\
\hline Case 1 & $\begin{array}{l}190 / 105 \\
140 / 80 \\
140 / 85 \\
160 / 90\end{array}$ & $\begin{array}{r}140 / 85 \\
85 / 50 \\
95 / 65 \\
110 / 70\end{array}$ & $\begin{array}{l}76 \\
74 \\
80 \\
74\end{array}$ & $\begin{array}{l}78 \\
95 \\
90 \\
82\end{array}$ & 1.9 \\
\hline Case 2 & $\begin{array}{l}115 / 80 \\
130 / 90\end{array}$ & $\begin{array}{l}75 / 55 \\
100 / ?\end{array}$ & $\begin{array}{l}76 \\
72\end{array}$ & $\begin{array}{l}80 \\
72\end{array}$ & \\
\hline Case 3 & \begin{tabular}{l|}
$115 / 75$ \\
$130 / 90$
\end{tabular} & $\begin{array}{l}100 / 70 \\
105 / 65\end{array}$ & $\begin{array}{l}69 \\
56\end{array}$ & $\begin{array}{l}74 \\
56\end{array}$ & \\
\hline $\begin{array}{r}\text { Controls } 1 \\
2 \\
3 \\
4 \\
5\end{array}$ & $\begin{array}{l}105 / 60 \\
105 / 60 \\
130 / 80 \\
100 / 70 \\
145 / 70\end{array}$ & $\begin{array}{r}95 / 70 \\
100 / 60 \\
135 / 80 \\
100 / 70 \\
145 / 70\end{array}$ & $\begin{array}{l}74 \\
68 \\
78 \\
62\end{array}$ & $\begin{array}{l}80 \\
78 \\
84 \\
66\end{array}$ & $\begin{array}{l}1.2 \\
0.9 \\
1.9\end{array}$ \\
\hline
\end{tabular}

not previously been recorded, and it was therefore measured in Cases 2 and 3 to see if a similar vasodilatation in muscle might be the cause of the low blood pressure in postural hypotension. A fall in blood pressure, whether caused by change in posture, trapping blood in the legs, or both, was accompanied by a fall in muscle blood flow on all occasions except one. From these experiments it was only possible to say that the response differed from that in fainting in which the muscle blood flow increases as the blood pressure falls, for the change in blood pressure made it impossible to decide whether the blood vessels had altered their diameter. In one experiment, however, although the systolic pressure was reduced to $45 \mathrm{~mm}$. $\mathrm{Hg}$ by sitting the patient up and trapping blood in the lower limbs, the forearm blood flow was unaltered. This experiment showed that some vasodilatation might occur, although not of the same order as that found in ordinary fainting.

An immediate and lasting fall in blood pressure on standing, like that found in cases of postural hypotension, may follow carotid sinus denervation (Capps and de Takats, 1938) or extensive sympathectomy. In both of these the carotid sinus reflex arc is disturbed, in the first case at its origin, in the second by severing the efferent nerves to the blood vessels of the viscera and lower limbs. Further, the effect of pressure on the carotid sinus in seven cases of postural hypotension has been reported (Table II). Only in the case of Agostoni is there a doubtfully significant response. In the three cases reported here direct pressure on either carotid sinus had no effect on pulse rate or blood pressure. Although pressure on the carotid sinus is without effect in 30 per cent of normal subjects (Weiss and Baker, 1933) this uniformity in idiopathic postural hypotension is highly significant, and with the similarity in the change in blood pressure on standing to that found in lesions affecting the carotid sinus reflex arc points directly to some lesion of that arc. Additional evidence was obtained by occluding the carotid arteries on one side or the other in Cases 1 and 2. This also failed to provoke any change in pulse rate or blood pressure. The parts of the carotid sinus reflex arc were therefore tested individually as far as possible.

The integrity of the peripheral sympathetic nerves was shown by a normal goose-skin response to faradism in all three cases, and all showed a normal rise in skin temperature with flushing of the skin on blocking the ulnar nerve with local anæsthetic. The peripheral sympathetic nerves were therefore functioning, and the peripheral vessels subject to vasomotor impulses travelling by the 
usual peripheral paths. Further evidence of vasomotor activity was a normal rise of skin temperature on heating the body obtained in all three cases. A similar response to heat has been recorded by Jeffers et al. (1941).

TABLE II

Carotid Sinus Pressure

\begin{tabular}{l|cc}
\hline \multicolumn{1}{c|}{ Authors } & Effect on : \\
& Pulse Rate & Blood Pressure \\
\hline Cappacioand Donald(1938) & Nil & S. up $10 \mathrm{~mm}$. Hg. \\
Jeffers et al. (1941) & Nil & S. down $10 \mathrm{~mm}$. Hg \\
Agostoni (1937) & Nil & S. down $20 \mathrm{~mm}$. Hg \\
East and Brigden (1946) & Slight slowing & Nil \\
Korns and Randall (1937) & Nil & Nil \\
Moretti (1934) & Nil & \\
$\begin{array}{l}\text { Davis and Schumway- } \\
\text { Davis (1937) }\end{array}$ & No carotid sensitivity & \\
\hline
\end{tabular}

In all three cases a normal diminution in finger volume and blood flow followed a deep breath. This is known to be a spinal reflex (Gilliat et al., 1948) with a sympathetic efferent path (Bolton et al., 1936). The sympathetic efferent nerves were therefore intact as far as the spinal reflex level.

The higher reflexes were then investigated. In all three cases, as in those described by Jeffers et al., and by Stead and Ebert, a fall in blood pressure was associated with a reduced blood flow in finger and hand, but these changes were within normal limits, and cannot be accepted as evidence of failure of vasoconstriction. Clear evidence of loss of reflex vasoconstriction was obtained by the response to other stimuli.

The effect of cold and pain and sudden noise was investigated in all the patients. For example, Case 1 lay down clothed, and was covered by blankets. After half an hour a plethysmograph was fitted to the right hand and an electric blanket placed round the right arm and forearm. After a further 30 minutes recording began. Room temperature was $19^{\circ} \mathrm{C}$., the plethysmograph temperature $34^{\circ} \mathrm{C}$. Immersion of the left hand to the wrist in ice water had no effect on the volume of the right hand. This observation was repeated six times, the left hand being warmed up till it felt hot to touch between each immersion. Application of ice to the patient's cheek also caused no change in hand volume.

On two other occasions similar results were obtained with the patient clothed, seated in a comfortable chair, and kept warm by blankets. Continuous immersion of one hand in ice water for two minutes, and intermittent immersion for $4 \frac{1}{2}$ minutes caused no change in the volume of the other hand, although the continued cold caused pain. Similarly, no change in hand volume occurred when the skin of the forearm was pricked with a pin. These experiments were done while the patient was being treated by the head-up bed regime, and her blood pressure seated was $120 / 80 \mathrm{~mm}$. Control observations on normal people showed that immersion of one hand in ice water, or pricking the skin, regularly showed a sharp fall in the volume of the other hand.

Similarly, in Case 2, no change in hand, finger, or forearm volume or blood flow was caused by ice applied to the cheek or by ice water to the hand. Similar results were obtained during faradism to the skin sufficient to raise a wheal, and by a sudden, unexpected, loud noise. Case 3 also failed to show any response in fingers or forearm to these stimuli (Fig. 1).

It is therefore concluded that the disorder of blood pressure regulation present in these three cases is due to a similar failure of the normal mechanism responsible for causing reflex vasoconstriction in response to a fall in blood pressure.

The lesion is likely to be above the spinal reflex level, either in the afferent nerves or the central mechanism. A lesion of the afferent nerves is thought to be unlikely because no reflex response 

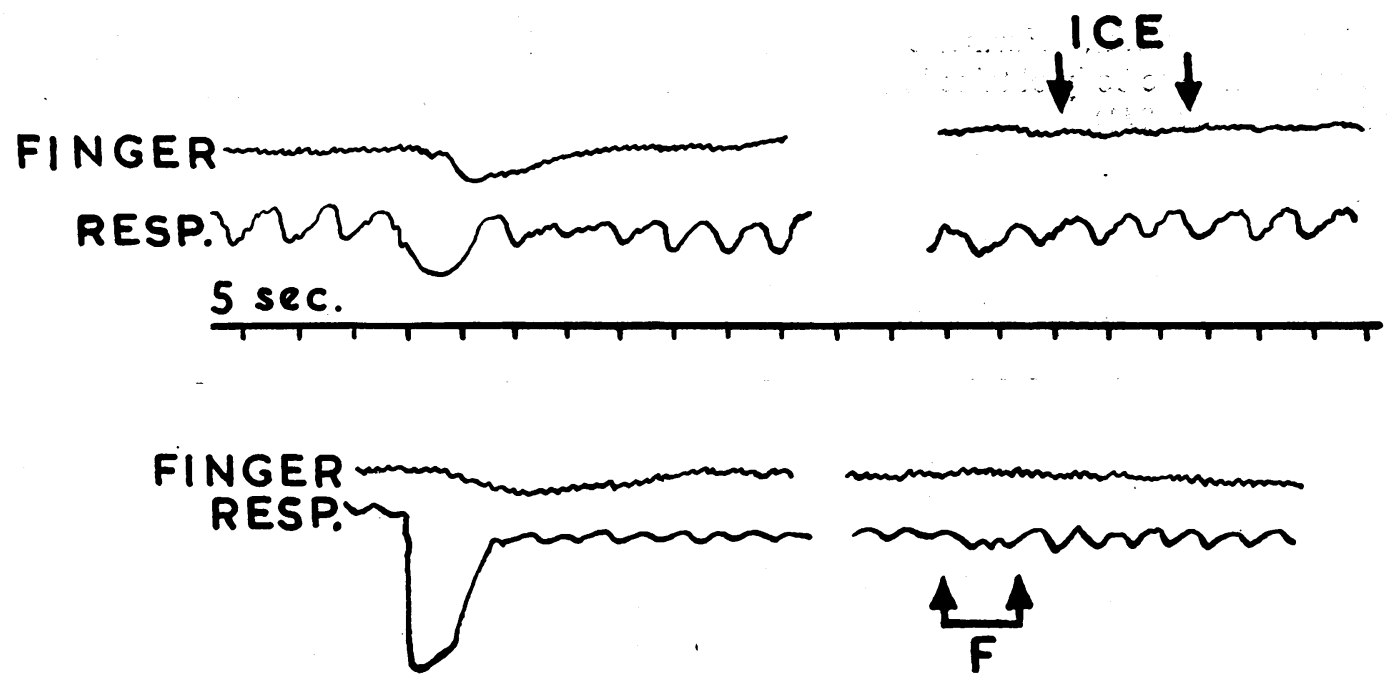

5 sec.

Fig. 1

Upper Record. CASE 2.-Normal response to deep inspiration, but no response to immersion of the other hand in ice water to the wrist. Plethysmograph temperature $35^{\circ} \mathrm{C}$, , room temperature $25^{\circ} \mathrm{C}$., patient comfortably warm.

Lower Record. CASE 3.-Normal response to deep inspiration, but no response to faradism (F) sufficient to raise a wheal, and to make him "catch his breath." Plethysmograph temperature $35^{\circ} \mathrm{C}$., room temperature $19 \cdot 5^{\circ} \mathrm{C}$, patient warm and comfortable.

was obtained from stimuli that were appreciated by the patient, and travelled by a variety of paths. A central lesion is therefore thought to be responsible.

Further localization by experiment has not been achieved, and the association of disturbances in the regulation of blood pressure, pulse rate, sweating, and sexual function which is found in this disease does not give any clear indication of the site likely to be affected. The disorder appears to be confined to the autonomic nervous system, and can show progression. Thus, in the first case reported, a fall in blood pressure at first caused a rise in pulse rate, while later the pulse became unchanging, and in a patient described by Ghrist and Brown (1928) anhidrosis was present on the right side for six years before becoming complete. The nature of the lesion, however, is quite obscure.

\section{SUMMARY}

Analysis of observations on three cases of postural hypotension provides strong evidence that the disorder is due to a central failure of the carotid reflex.

I wish to thank Dr. C. G. Baker and Mr. Harvey Jackson for access to Cases 2 and 3 respectively. Many of the observations on the first case are abstracted from a thesis for the M.D. degree submitted during an appointment as Assistant in the Department of Medicine in the University of Aberdeen.

\section{REFERENCES}

Agostoni, G. (1937). Arch. mal. Coeur., 30, 91.

Barcroft, H., and Edholm, O. G. (1945). J. Physiol., 104, 161.

Bolton, B., Carmichael, E. A., and Sturup, G. (1936). Ibid., 86, 83.

Bradbury, S., and Eggleston, C. (1925). Amer. Heart J., 1, 73.

Cappacio, G. D., and Donald, C. J. (1938). J. Amer. med. Ass., 110, 1180. 
Capps, G. D., and de Takats, G. (1938). J. clin. Invest., 17, 385.

Davis, P. L., and Schumway-Davis, M. (1937). J. Amer. med. Ass., 108, 1247.

East, T., and Brigden, W. (1946). Brit. Heart J., 8, 103.

Flack, M. (1921). Lancet., 2, 637.

Ghrist, D. G., and Brown, G. E. (1928). Amer. J. med. Sci., 175, 336.

Gilliat, R. W., Guttman, L., and Whitteridge, D. (1948). J.' Physiol., $107,67$.

Jeffers, A., Montgomery, H., and Burton, A. C. (1941). Amer. J. med. Sci., 202, 1.

Korns, H. M., and Randall, W. I. (1937). Amer. Heart J., 13, 114.

Lewis, T. (1932). Brit. med. J., 1, 873.

MacLean, A. R., and Allen, E. V. (1940). J. Amer. med. Ass., 115, 2163.

,-- and Magath, T. B. (1944). Amer. Heart J., 27, 145.

Moretti, E. (1934). Zentralbl. inn. Med., 55, 497.

Smirk, F. H. (1933). J. Physiol., 78, 113.

Stead, E., and Ebert, R. V. (1941). Arch intern. Med.; 67, 546.

Weiss, S., and Baker, J. P. (1933). Medicine, 12, 298. 